\title{
Toxoplasma gondii seropositivity and risk factors in pregnant women followed up by the Family Health Strategy
}

\author{
Rosiléia Marinho de Quadros ${ }^{[1]}$, Gino Chaves da Rocha ${ }^{[2]}$, Getúlio Romagna ${ }^{[1]}$, \\ Juliana Pellizzoni de Oliveira ${ }^{[1]}$, Dadryhan Morghani Ribeiro ${ }^{[1]}$ \\ and Sandra Márcia Tietz Marques ${ }^{[3]}$
}

[1]. Departamento de Ciências Biológicas e da Saúde, Universidade do Planalto Catarinense, Lages, Santa Catarina, Brasil. [2]. Laboratório de Parasitologia e Doenças Parasitárias, Faculdade de Medicina Veterinária e Agronomia, Universidade de Brasília, Brasília, Distrito Federal, Brasil. [3]. Departamento de Patologia Clínica Veterinária, Faculdade de Medicina Veterinária, Universidade Federal do Rio Grande do Sul, Porto Alegre, Rio Grande do Sul, Brasil.

\begin{abstract}
Introduction: Toxoplasmosis is a zoonotic infection caused by Toxoplasma gondii. It is transmitted by the ingestion of contaminated water and foods, by soil contaminated with cat feces, especially while handling it, and congenitally via the placenta. The diagnosis of maternal infection is made by serological detection of either IgM or IgG antibodies. This study assessed the seropositivity in pregnant women followed up by the Family Health Strategy (FHS) in Lages, Santa Catarina, Brazil. Methods: The study was performed in 19 FHS units and included 148 childbearing women. The outcomes evaluated were IgM and IgG seropositivity and behavioral variables. Results: IgG yielded positive results in 16\% of the pregnant women, whereas IgM was positive in only $1 \%$. Conclusions: The $1 \% \operatorname{IgM}$ positivity rate for $T$. gondii indicates congenital toxoplasmosis is not common in Lages.
\end{abstract}

Keywords: Toxoplasmosis. Pregnant women. Epidemiology.

Toxoplasmosis is a zoonotic infection that affects several animal species, but the cat is the definitive host. Human infection by Toxoplasma gondii may be acquired or congenital. The acquired infection occurs after the ingestion of contaminated raw or undercooked meat, contaminated water, and soil contaminated with cat feces, especially while handling it during gardening or horticultural activities. Congenital infection is more frequent in pregnant women who develop acute infection up to the third trimester of gestation. However, the symptomatic and most severe cases, which may involve chorioretinitis, brain calcifications, delayed neuropsychomotor development, microcephaly, and macrocephaly, occur when maternal infection develops in the first two trimesters, during which it may cause fetal death $^{(1)}$.

The diagnosis of human infection during pregnancy is especially important owing to the severity of lesions, which are often permanent ${ }^{(2)}$. Early diagnosis and adequate treatment of pregnant women have reduced fetal transmission rates

Corresponding author: Dra. Rosileia Marinho de Quadros. Faculdade de Biomedicina/UNIPLAC. Av. Castelo Branco 170, Universitário, 88509-900 Lages, Santa Catarina, Brasil.

Phone: 5549 3251-1022; Fax: 5549 3251-1051

e-mail: rosileia18@hotmail.com

Received 1 October 2014

Accepted 3 December 2014 and, consequently, the number of cases involving intrauterine infection $^{(3)}$.

The Family Health Strategy (FHS) is a public health policy developed by the Brazilian Ministry of Health in 1994 and is an integral part of the National Primary Healthcare Policy. The FHS covers $31 \%$ of the Brazilian population. The health teams operate mainly at primary health units and in the community. The FHS priorities are prevention, promotion, and restoration of health in a holistic manner. Healthcare is provided by physicians, dentists, nurses, nursing assistants, and community health agents (the Family Health team) $)^{(4)}$.

The aims of this study were to determine toxoplasmosis seropositivity in pregnant women followed up at FHS units during prenatal care and to determine the variables (age, place of residence, occupation, gestational period, and presence of cats, among others) associated with a higher toxoplasmosis seroprevalence.

The study was conducted in 19 FHS units located in 14 peripheral neighborhoods of Lages, State of Santa Catarina, Brazil, in 2008 and 2009. A total of 148 pregnant women with different gestational periods were surveyed. All participants signed an informed consent form. A previously standardized questionnaire was used for data collection. The serological detection of immunoglobulin $\mathrm{M}$ (IgM) and immunoglobulin $\mathrm{G}(\mathrm{IgG})$ antibodies, based on the results of serological tests performed during prenatal care, and related sociodemographic 
and behavioral variables for the assessment of eating and hygiene habits were taken into consideration. The questionnaire included data on pregnancy and on the pregnant women: age, schooling (illiteracy, incomplete elementary education, complete elementary education, incomplete high school education, complete high school education, or college education), occupation (homemaker, housemaid/housekeeper, cleaner/cook, sales clerk/store clerk, or other), place of residence (urban or rural area), and parity.

The following risk factors for toxoplasmosis were considered during the weekly questionnaire completed at FHS units: preparation of meals at home, eating habits and consumption of raw or undercooked meat, adequate food sanitation, presence of cats in the home, presence of cats around the house, dirt backyards, gardening or growing vegetables in a kitchen garden, and habit and frequency of eating out (eating out at least twice a week was regarded as frequent). Pregnant women were also asked about their knowledge regarding toxoplasmosis (such as modes of contamination and infection and the consequences the disease could have for their children) as well as the number of prenatal visits, whether they had access to prenatal care in previous pregnancies or were primiparous, and gestational age. EpiData 3.1 software was used to construct the database. To avoid potential errors, the data were entered twice and later checked using the partial and full reports. The same statistical package was used for the descriptive analysis (epidemiological profile of reactive pregnant women), while the $\chi^{2}$ test was utilized for possible associations between outcome variables and the risk factors related to seropositivity.

A total of 148 pregnant women were interviewed at 19 FHS units. Our results revealed an IgG positivity of $16 \%$ and an IgM positivity of $1 \%$. However, for a large number of respondents, there were no results for IgG $(39 \%)$ or $\operatorname{IgM}(31 \%)$. The largest proportion of pregnant women were 18 to 21 years old $(33 \%)$, the youngest was 14, and the oldest was 41 (Figure 1). Concerning schooling, $27 \%$ had not completed an elementary education, $28.4 \%$ had completed a high school education, and only $1.4 \%$ was illiterate. As the primary occupation, $75 \%$ of the women were homemakers (Figure 2). Almost half (48\%) of the pregnant women were primiparous, whereas the remainder had one or more children (Figure 3). Regarding food preparation, $86 \%$ of pregnant women prepared their meals at home, and $50 \%$ of them did not change their eating habits during pregnancy. Approximately $51 \%$ did not usually eat out, and most $(80 \%)$ did not eat raw or undercooked meat. When asked about the sanitation of vegetables and legumes (standard use of a dilute bleach solution), approximately $71 \%$ responded they usually washed them.

Regarding the presence of cats in the household, $70 \%$ did not have cats in the home, but $68 \%$ mentioned the presence of these animals in the neighborhood. Most of the respondents lived in houses with dirt backyards (65.5\%), and $44 \%$ of them

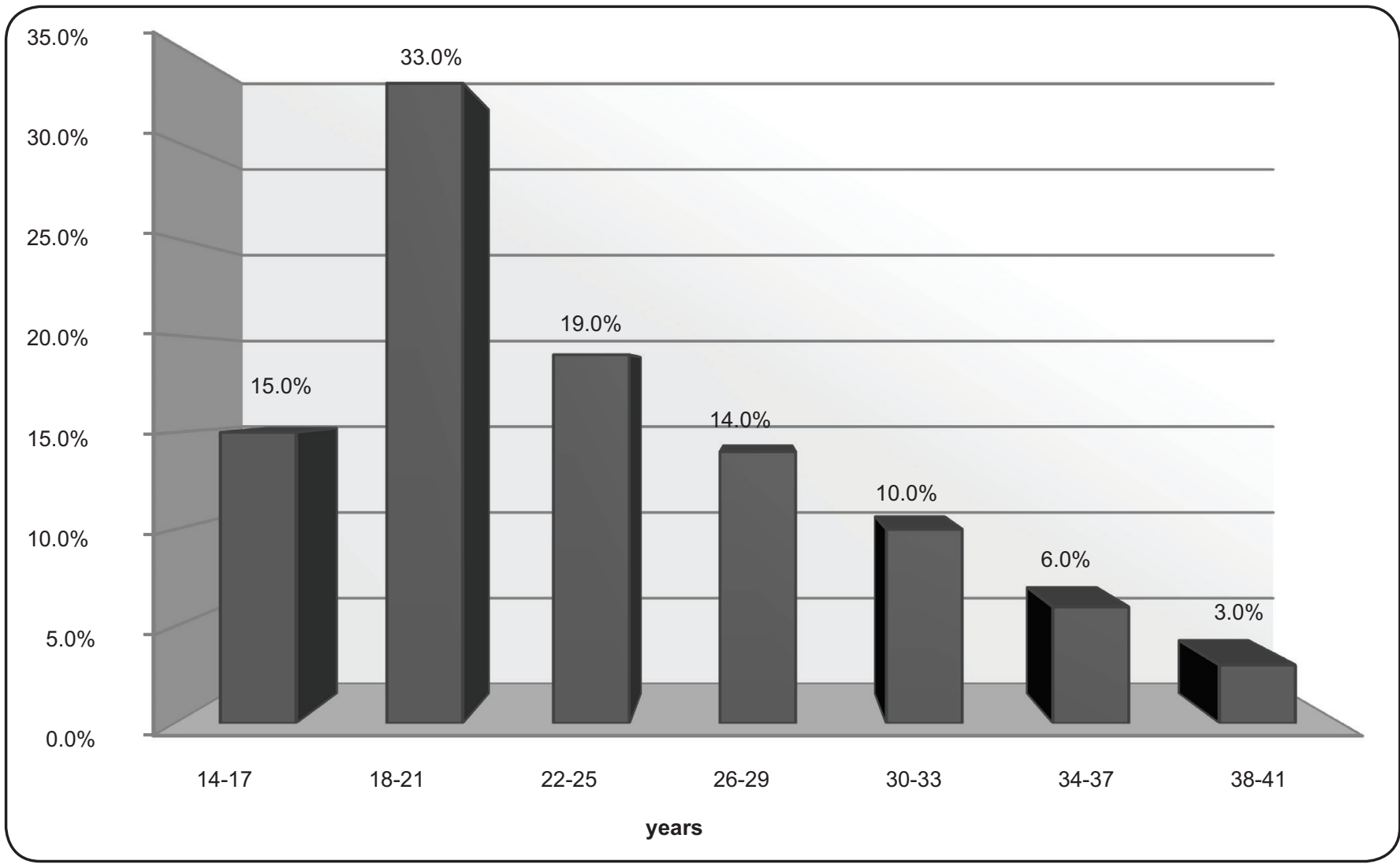

FIGURE 1 - Proportion of pregnant women, according to age, followed up by the Family Health Strategy in peripheral neighborhoods of Lages, State of Santa Catarina, Brazil, in 2008 and 2009. 


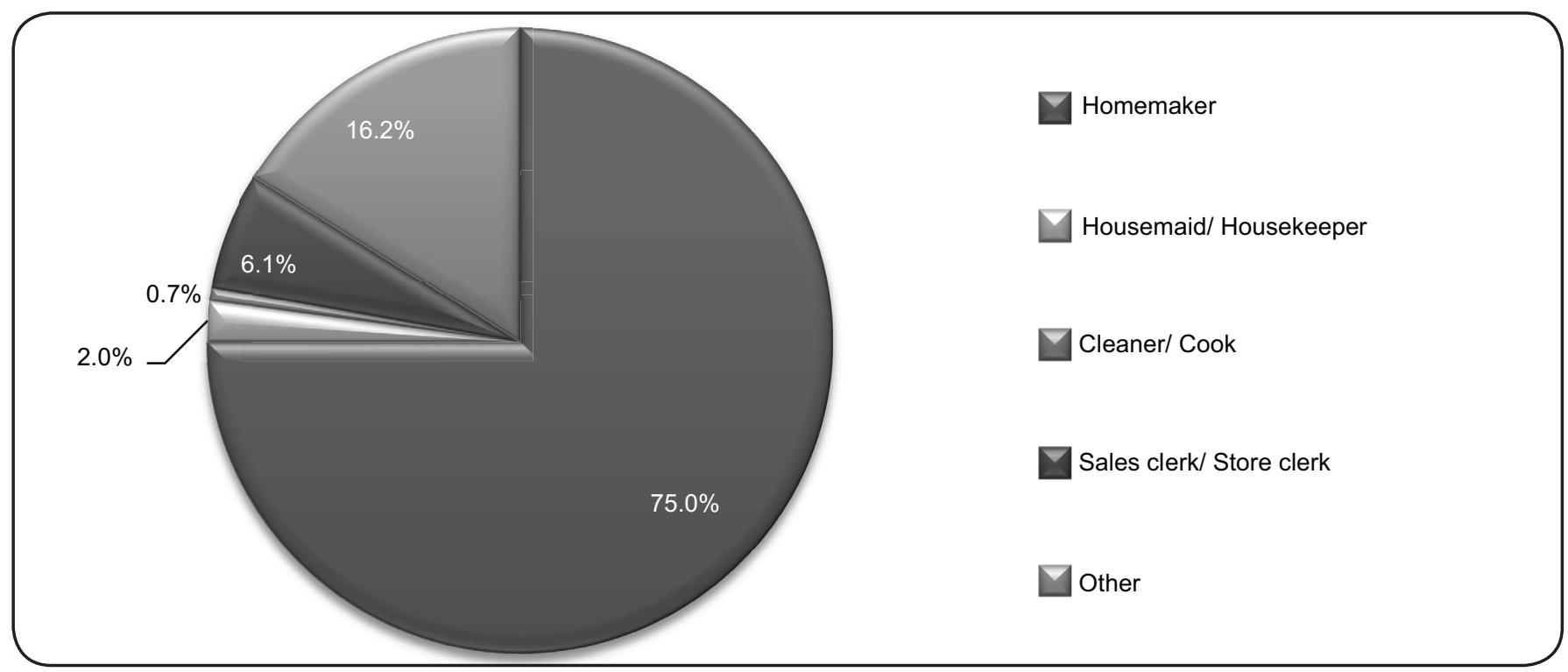

FIGURE 2 - Primary occupations of pregnant women followed up by the Family Health Strategy in peripheral neighborhoods of Lages, State of Santa Catarina, Brazil, in 2008 and 2009.

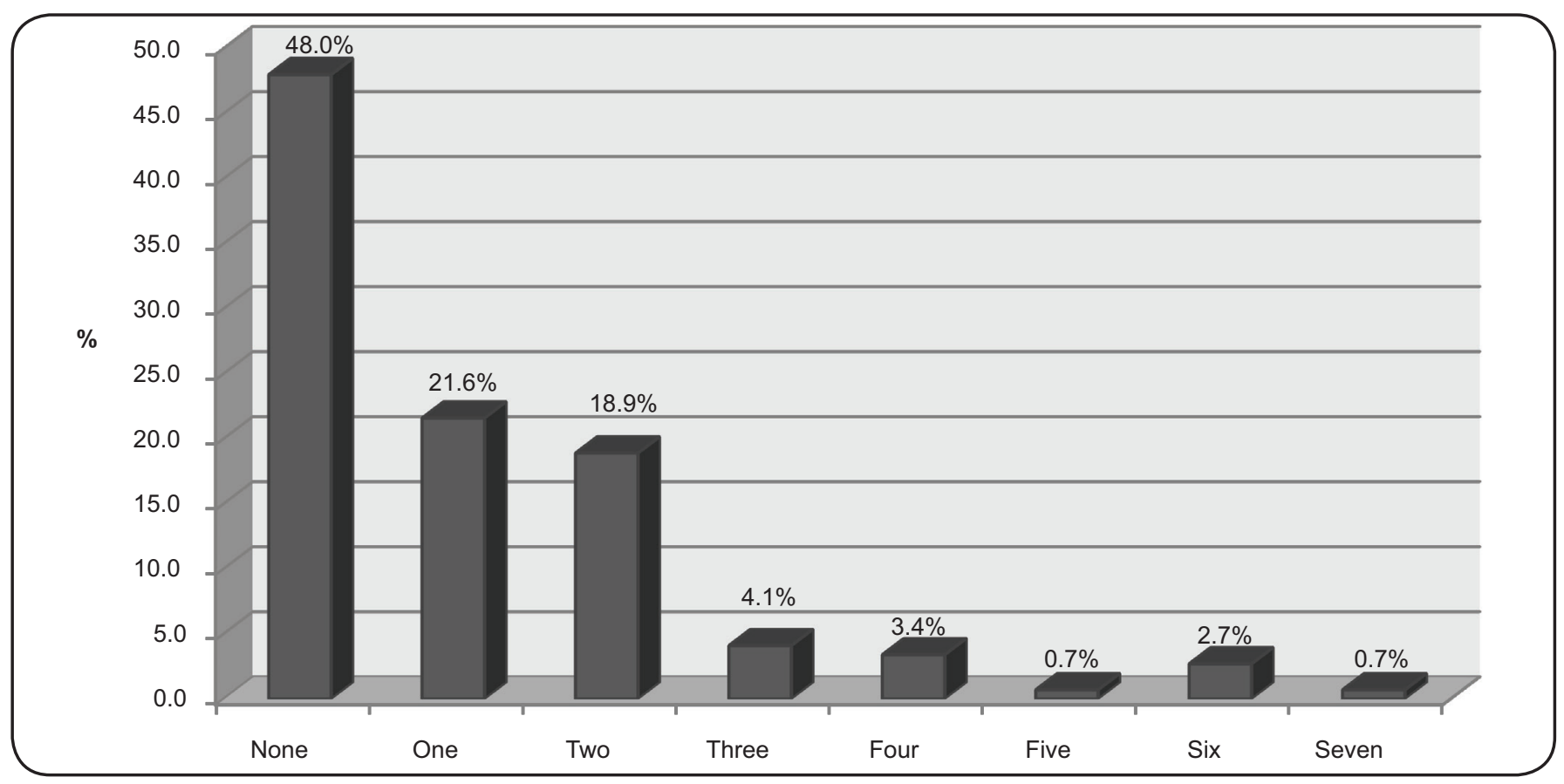

FIGURE 3 - Distribution of the number of children of pregnant women followed up by the Family Health Program in peripheral neighborhoods of Lages, State of Santa Catarina, Brazil, in 2008 and 2009.

engaged in gardening activities on a regular basis. When asked about toxoplasmosis, $56 \%$ had heard of it, but $51 \%$ did not know about the modes of infection, $51 \%$ did not know about the consequences of the disease for their babies, and 51.4\% were not aware of the importance of being tested.

The average number of prenatal visits was around five, and only $5 \%$ of the pregnant women attended all monthly appointments, as recommended by the Unified Health System; approximately $60 \%$ had prenatal care in previous pregnancies.

The seropositivity of $1 \%$ for $\operatorname{IgM}$ and $16 \%$ for IgG detected in this study demonstrates that congenital toxoplasmosis is not common in Lages. However, this finding could be underestimated, due possibly to the small number of women who use the FHS program. Among the patients followed up at 
the 19 FHS units, compliance with the study was an issue, as they did not turn up for scheduled prenatal care visits or were unaware of the importance of having prenatal care throughout the gestational period. In our opinion, the FHS is an excellent program for pregnant women, being likened to primary healthcare programs in European countries ${ }^{(5)}$ such as France $^{(6)}$, Poland $^{(7)}$, and Austria ${ }^{(8)}$, as well as the United States ${ }^{(9)}$.

When asked about toxoplasmosis, none of the pregnant women were knowledgeable about the disease, the modes of transmission, or prophylactic measures. In addition, most health records did not have any ELISA-based results or titers for the detection of $\operatorname{IgG}$ and IgM antibodies against $T$. gondii; they contained only information on whether the test was reactive or nonreactive. Furthermore, IgM results for Brazilian pregnant women, using the same diagnostic method (ELISA), vary widely, as demonstrated in São Paulo $(56.6 \%)^{(10)}$, in the Northwest of Rio Grande do Sul $(74.6 \%)^{(1)}$, and in Bahia $(64.9 \%)^{(11)}$. Lower reactive IgM titers were detected in pregnant women from Vitoria, in the State of Espírito Santo $(2.2 \%)^{(12)}$, and in poor women from the countryside of the State of São Paulo $(1.3 \%)^{(13)}$. However, the IgM rate of $1 \%$ found in Lages was higher than that observed in the northwest of the State of São Paulo, where none of the 232 pregnant women was positive for $\operatorname{IgM}^{(14)}$.

Regarding the statistical association between the outcome variables (IgG and $\operatorname{IgM}$ seropositivity) and the independent variables, the $\chi^{2}$ test calculated for IgG-positive and IgMpositive pregnant women compared to the results obtained for those women who owned a cat in the home was not statistically significant; however, there exists positive correlation with IgG seropositivity for those who engaged in gardening activities. The odds ratio revealed that pregnant women working in the garden increased their chance of being IgG-positive by 1 , but the same does not apply to IgM.

The outskirts of Lages are characterized by a large amount of stray cats and dogs, which live in the streets or are allowed by their owners to wander free. This ends up facilitating the contact of these animals with diseased ones, causing them to be infected, and thus, they eventually carry pathogens into their owners' households. In the soil, $T$. gondii oocysts shed in the feces may survive for up to 18 months at different temperatures. High humidity levels and low temperatures increase the viability of pathogenic structures in the environment, where soil contamination appears to be the best direct indicator of the risk of infection parasites pose to both humans and animals ${ }^{(9)}$. Lages is a town located in the mountain region of the state of Santa Catarina, with subtropical climate, and an average annual temperature of $14.3^{\circ} \mathrm{C}$, where harsh and rainy winters predominate, thereby contributing to the positive correlation between IgG seropositivity in pregnant women and gardening.

Toxoplasmosis is regarded as a worldwide public health problem owing to its frequency of seroconversion and to the potentially severe clinical sequelae inflicted on infected children $^{(6)}(7)$. France provides an example of a reduction in toxoplasmosis prevalence, where hygiene measures and changes in eating habits contributed to decreasing the prevalence of toxoplasmosis among pregnant women from 54.3\% in 1995 to
$43.8 \%$ in $2003^{(6)}$. Epidemiological studies on risk factors and on assessments of the importance of educating the population indicate massive informational programs about toxoplasmosis help reduce its prevalence in developed and developing countries ${ }^{(15)}$.

Brazilian public policies must be improved so that information about toxoplasmosis is available to people in all social classes. The Unified Health System program guidelines recommend that municipalities promote and develop primary healthcare actions. Municipalities must keep up-to-date records on the prevalence and risk factors of toxoplasmosis and heavily invest in education about this disease, using appropriate and simple language, especially at health centers, in addition to qualified and motivated health teams so that pregnant women from poorer communities acknowledge the value of and participate regularly in this monitoring program.

In conclusion, most pregnant women did not have basic information about toxoplasmosis during pregnancy. The 1\% rate of positive IgM for $T$. gondii observed in the present study indicates that congenital toxoplasmosis is uncommon in Lages.

\section{Ethical considerations}

The research protocol was submitted to the Research Ethics Committee of the Universidade do Planalto Catarinense (UNIPLAC), approved, and registered under number 032-05 and authorized by the FHS technical coordinator.

\section{CONFLICT OF INTEREST}

The authors declare that there is no conflict of interest.

\section{REFERENCES}

1. Spalding SM, Amendoeira MR, Ribeiro LC, Silveira C, Garcia AP, Camilo-Coura L. Estudo prospectivo em gestantes e seus bebês com risco de transmissão de toxoplasmose congênita em um município do Rio Grande do Sul. Rev Soc Bras Med Trop 2003; 36:483-491.

2. Diniz EMA. O diagnóstico da toxoplasmose na gestante e no recém-nascido. Pediatria 2006; 28:222-225.

3. Roizen N, Swisher CN, Stein MA, Hopkins J, Boyer KM, Holfels E, et al. Neurologic and developmental outcome in treated congenital toxoplasmosis. Pediatrics 1995; 95:11-20.

4. Ministério da Saúde. Saúde da Família (Internet). Brasília: Ministério da Saúde; 2013. (Cited 2013 November 4). Available at: http://dab.saude.gov.br/atencaobasica.php

5. Mittal V, Ichhpujani RL. Toxoplasmosis an update. Trop Parasitol 2011; 1:9-14.

6. Garcia-Méric P, Franck J, Dumon H, Piarroux R. Prise en charge de la toxoplasmose congénitale en France: données actuelles. Presse Méd 2010; 39:530-538.

7. Benard A, Petersen E, Salamon R, Chene G, Gilbert R, Salmi LR. Survey of European programmes for the epidemiological surveillance of congenital toxoplasmosis. Eurosurveillance 2008; 13:1-7.

8. Prusa AR, Kasper DC, Olischar M, Husslein P, Pollak A, Hayde M. Evaluation of serological prenatal screening to detect Toxoplasma gondii infections in Austria. Neonatology 2013; 103:27-34. 
9. Lopez A, Dietz VJ, Wilson M, Navin TR, Jones JL. Preventing congenital toxoplasmosis. MMWR Recomm Rep 2000; 49:59-68.

10. Mandai N, Lopes FMR, Mitsuka-Breganó R. Prevalência de anticorpos $\operatorname{IgG}$ e IgM anti-Toxoplasma gondii em gestantes atendidas nas unidades básicas de saúde do município de Londrina - Paraná, no período de 2003 e 2004. Rev Bras Anal Clin 2007; 39:247-249.

11. Nascimento I, Carvalho S, Cardozo N, Asfora S, Campo A, Menezes A, et al. Estudo da prevalência de anticorpos antiToxoplasma gondii em mulheres grávidas no Estado da Bahia. Rev Ciên Med Biol 2010; 1:12-15.

12. Areal KR, Miranda AE. Soroprevalência de toxoplasmose em gestantes atendidas na rede básica de saúde de Vitória, ES. News Lab 2008; 87:122-129.
13. Kawasakil ML, Carvalho PN, Lucarevshi BR. Atenção à toxoplasmose durante a gestação em população carente do interior do Estado de São Paulo. Pediatria 2006; 28:242-250.

14. Galisteu KJ, Mattos CB, Lélis AGL, Oliveira MP, Spejorim LCJF, Jordão $\mathrm{P}$, et al. Prevalência e fatores de risco associados à toxoplasmose em grávidas e suas crianças no Noroeste Paulista, Brasil. Rev Panam Infectol 2007; 9:24-29.

15. Ferguson W, Mayne PD, Cafferkey M, Butler K. Lack of awareness of risk factors for primary toxoplasmosis in pregnancy. J Med Sci 2011; 180:807-811. 